\title{
Melanoma awareness and prevalence of dermoscopic examination among internet users: a cross-sectional survey
}

\author{
Grazyna Kaminska-Winciorek ${ }^{1}$, Jerzy Wydmanski², Maksymilian Gajda ${ }^{3}$, Andrzej Tukiendorf ${ }^{4}$ \\ ${ }^{1}$ The Center for Cancer Prevention and Treatment, Katowice, Poland \\ 2Department of Conventional and Intraoperative Radiotherapy, Maria Skłodowska-Curie Memorial Cancer Centre and \\ Institute of Oncology Gliwice Branch, Gliwice, Poland \\ ${ }^{3}$ Clinical Oncology Ward, Starkiewicz Specialized Hospital, Dąbrowa Górnicza, Poland \\ ${ }^{4}$ Department of Epidemiology, Maria Skłodowska-Curie Memorial Cancer Centre and Institute of Oncology Gliwice Branch, Gliwice, \\ Poland
}

Adv Dermatol Allergol 2016; XXXIII (6): 421-428

DOI: $10.5114 /$ pdia.2016.63297

\begin{abstract}
Introduction: Melanoma presents the greater threat to health the later the disease is detected and treated, although treatment results can be improved by the widespread use of dermoscopy. However, scarce data are available concerning the awareness of dermoscopy and the frequency of its performance in the non-patient population. Aim: To assess the awareness of melanoma detection by dermoscopic examination among the audience of a scientific website.

Material and methods: Respondents were invited to participate in an online cross-sectional survey. They were asked to complete an online questionnaire designed by the authors. The preliminary analysis of 5,154 collected forms and the exclusion of incomplete forms yielded 4,919 fully completed questionnaires; the resulting database was analyzed statistically using logistic regression with the R software program $(95 \% \mathrm{Cl})$.

Results: Less than two-fifths (39.2\%) of respondents reported ever having sought the advice of a medical professional (dermatologist or other specialist), and $25.4 \%$ of the respondents had undergone dermoscopy at least once in their life. Furthermore, approximately one-tenth of respondents (10.7\%) were not aware of this detection tool. The study respondents gained knowledge about dermoscopic examination from television and magazines. The performance of dermoscopy was more increasingly associated with inhabitants of larger locales, the use of higher-SPF sunscreens, and greater awareness of the relationship between the risk of melanoma and sunburn.

Conclusions: Awareness of melanoma and sun care varied within the analyzed population. A subset of individuals at high risk of melanoma was identified. This group included those who engaged in risky sun exposure behaviors and who had never been examined by dermoscopy.
\end{abstract}

Key words: melanoma, awareness, dermoscopy, education, internet.

\section{Introduction}

Melanoma accounts for approximately three-quarters of all deaths from skin cancer worldwide and presents the greater threat the later the disease is detected and treated. The incidence of this malignancy exhibits geographic diversity and primarily depends on age, gender, and race $[1,2]$. Comprehensive educational and screening campaigns implemented in underserved areas and in geographic regions with higher survival rates have influenced early melanoma detection [3]. The incidence of melanoma in Poland is less than half of the European Union (EU) average (4.1 vs. 10.2). However, despite this lower incidence, Poland has one of the highest mortalityto-incidence rate ratios in Europe (0.49) and more reported deaths from melanoma than the EU (2.0 vs. 1.6, respectively) [2]. Therefore, other affecting factors, such as late detection and incomplete reporting of new melanoma cases, should also be considered. Poor access to health care, low gross domestic product, and educational level may play an important role in the late diagnosis and treat-

Address for correspondence: Grazyna Kaminska-Winciorek MD, PhD, The Center for Cancer Prevention and Treatment, 16 Fliegera St, 40-060 Katowice, Poland, fax/cell phone: +48 698626 208, e-mail: dermatolog.pl@gmail.com

Received: 23.02.2016, accepted: 6.09.2016. 
ment of melanoma [4]. Indeed, it is likely that these issues, along with low awareness among the general public, may lead to poor accessibility to dermatologists and dermoscopic examination, resulting in an unfavorable prognosis for patients who are diagnosed with melanoma. This adverse situation may be improved by educational programs combined with adequate diagnostic screening methods, including dermoscopy (also known as dermatoscopy and epiluminescence microscopy). The sensitivity of dermoscopy in the detection of melanoma is $83 \%$ with a specificity of $69 \%$ [5]. When performed by a trained specialist, dermoscopy has a greater discriminatory power for melanoma than clinical examination alone [3, 6]. Dermoscopy also enables avoidance of unnecessary surgical excisions [7]. Scarce data are available concerning the frequency of dermoscopy performance in the diagnosis of melanocytic lesions in the European population.

\section{Aim}

The aim of this study was to assess the awareness of melanoma detection by dermoscopic examination among the audience of a scientific website.

\section{Material and methods}

This cross-sectional web-based study was designed according to our former study [8], ensuring ease of gathering information and the ability to reach a large number of respondents. Web data acquisition, consisting of the

Table 1. Demographic characteristics of the analyzed group of 4,919 respondents

\begin{tabular}{|c|c|c|c|}
\hline Characteristics & Group & $\begin{array}{l}\text { No. of } \\
\text { respondents }\end{array}$ & $\%$ \\
\hline $\begin{array}{l}\text { Age: } 29.4 \pm 12.8 \\
(11-92)\end{array}$ & Total & 4,919 & \\
\hline \multirow[t]{2}{*}{ Gender } & Males & 968 & 19.7 \\
\hline & Females & 3,951 & 80.3 \\
\hline \multirow{5}{*}{$\begin{array}{l}\text { Place of } \\
\text { residence }\end{array}$} & Village & 1,237 & 25.1 \\
\hline & $<20$ thousand & 529 & 10.8 \\
\hline & 20-200 thousand & 1,194 & 24.3 \\
\hline & 200-500 thousand & 685 & 13.9 \\
\hline & $>500$ thousand & 1,274 & 25.9 \\
\hline \multirow[t]{5}{*}{ Education } & None & 93 & 1.9 \\
\hline & Elementary school & 132 & 2.7 \\
\hline & High school $1^{\text {st }}$ degree & 501 & 10.2 \\
\hline & High school $2^{\text {nd }}$ degree & 1,863 & 37.9 \\
\hline & $\begin{array}{l}\text { Master's degree and } \\
\text { beyond }\end{array}$ & 2,330 & 47.4 \\
\hline
\end{tabular}

respondents' answers to the questionnaire, was conducted from 20 March 2012 to 1 June 2012. Anonymous web surfers who had visited a Polish open-access scientific website entitled "Naukowy.pl" [9] which has been published since 1999 (targeting primarily young, educated readers) were invited to take part in a survey questionnaire. Each participant was informed about the purpose and fully anonymous character of the survey. The design of the survey required prior consent given by each invited individual. The consent was declared in an electronic form. At the same time every potential respondent was informed of the survey's aims and use of collected data only for scientific purposes. Both the agreement and disagreement were stored in the so-called "cookie" file, which also limited the possibility of re-participation. According to the Institutional Review Board of the Cancer Centre and Institute of Oncology (Gliwice, Poland), our study did not require their approval. The self-completion, user-friendly questionnaire was administered in an electronic format. The Google Docs platform was used for preparation and storage of the data [10]. The participants answered questions independently via a web browser. After answering all of the required questions, the responses were saved in a spreadsheet. No data were stored that were likely to identify the respondents (e.g. IP addresses). After the preliminary analysis of 5,154 collected forms and the exclusion of incomplete forms, 4,919 fully completed forms were obtained. The demographic characteristics of the respondents are reported in Table 1. The questionnaire, which was designed by the authors, contained a total of 61 questions written in Polish that were mainly closed-ended (47 questions, Q). The questions were divided into three sections related to demographic data, primary prevention responses, and secondary prevention. The first part of the survey assessed demographic data (age, gender, place of residence, education); the second part queried characteristics of respondents' behaviors regarding melanoma prevention (occupation, sunbathing, tanning in sun-beds, sunburn, the use of cosmetics with ultraviolet (UV) protection including UVAand UVB-protective agents, Fitzpatrick phototype, and a family history of melanoma); and the final part concerned secondary melanoma prevention, specifically selfperformed skin examination, dermoscopic assessment, and surgical excision of skin lesions. The respondents were also asked about clinical types and symptoms that might indicate the development of melanoma.

\section{Statistical analysis}

The statistical analysis was conducted on completed questionnaires with the R software [11]. We compared qualitative and quantitative data correlated with binomial responses using multivariate logistic regression. Response variables were binomially coded as $0=\mathrm{NO}$ (negative) and $1=$ YES (positive). The interpretation of 
the results was based classically on the odds ratio (OR) and $95 \%$ confidence intervals $(95 \% \mathrm{Cl})$.

\section{Results}

Only data on dermoscopic examination being the aim of this study are presented in the results section. The statistically significant $(p<0.05)$ results are reported in Tables 2-4.

\section{Group characteristics of individuals who underwent dermoscopic assessment in their lifetimes (Table 2)}

Less than two-fifths (39.2\%) of respondents had ever sought the advice of a medical professional (dermatologist or other specialist). Older respondents and those living in larger cities more frequently sought the advice of a dermatologist or other physician specialist for the evaluation of so-called pigmented moles. These individuals also used sunscreen creams over longer periods (years), more frequently repeated the application of these creams during a sunbathing session, and used sunscreens with higher sun protection factor (SPF) values. This group of respondents was also able to classify their skin into phototypes, depending on responsiveness to sunlight or the appearance of sunburn or a tan. They also recognized melanoma as one of the most malignant types of cancer (Q49).

$25.4 \%$ of participants claimed to have undergone dermoscopy at least once in their lifetimes. The performance of dermoscopic examination (Q44) was more highly associated with individuals who lived in more populous areas, used higher SPF-value products, knew that a history of sunburns increases the risk of melanoma up to five fold, and spent less time working outdoors. Dermoscopic assessment of melanocytic lesions was more often performed on individuals who used sunscreen creams for longer periods of their life (in years) and who more frequently (hourly) reapplied sunscreen during sunbathing. These individuals also used sunscreens with higher SPF values and knew that a history of sunburn increases the risk of melanoma up to five fold. These individuals also more frequently used protective eyeglasses when using tanning beds (Q46).

Table 2. Characteristics of the respondents who have ever sought skin assessment

\begin{tabular}{|c|c|c|c|c|}
\hline Response & Predictor & Odds ratio & $95 \% \mathrm{Cl}$ & $P$-value \\
\hline \multirow{7}{*}{$\begin{array}{l}\text { Q39 Have you ever } \\
\text { sought the advice of } \\
\text { a dermatologist or other } \\
\text { physician specialist for } \\
\text { the evaluation of so-called } \\
\text { pigmented moles? }\end{array}$} & Q1 Your age [years] & 1.01 & $1.01-1.02$ & $<0.001$ \\
\hline & Q3 Place of residence & 1.06 & $1.01-1.1$ & 0.008 \\
\hline & $\begin{array}{l}\text { Q11 If you use sunscreen creams, indicate for how many } \\
\text { years }\end{array}$ & 1.02 & $1.01-1.03$ & $<0.001$ \\
\hline & $\begin{array}{l}\text { Q13 Do you repeat the application of sunscreen cream during } \\
\text { sunbathing sessions? }\end{array}$ & 1.19 & $1.04-1.36$ & 0.012 \\
\hline & Q17 What SPF value do you use? & 1.01 & $1.0062-1.0138$ & $<0.001$ \\
\hline & $\begin{array}{l}\text { Q33 Can you classify your skin according to phototype } \\
\text { depending on its responsiveness to sunlight and the } \\
\text { appearance of sunburn or a tan? }\end{array}$ & 1.33 & $1.17-1.51$ & $<0.001$ \\
\hline & $\begin{array}{l}\text { Q37 Did you know that melanoma is one of the most } \\
\text { malignant types of cancer? }\end{array}$ & 1.68 & $1.39-2.03$ & $<0.001$ \\
\hline \multirow{4}{*}{$\begin{array}{l}\text { Q44 Have you ever had } \\
\text { a dermoscopic examination } \\
\text { performed? } \\
(25.4 \%)\end{array}$} & Q3 Place of residence & 1.05 & $1.01-1.1$ & 0.023 \\
\hline & Q7 For how long do you usually work outdoors? & 0.95 & $0.91-0.99$ & 0.043 \\
\hline & Q17 What SPF value do you use? & 1.0086 & $1.0048-1.0124$ & $<0.001$ \\
\hline & $\begin{array}{l}\text { Q30 Do you know that a history of sunburn increases the } \\
\text { risk of melanoma up to five fold? }\end{array}$ & 1.29 & $1.09-1.54$ & 0.004 \\
\hline \multirow[t]{5}{*}{$\begin{array}{l}\text { Q46 Were the nevi } \\
\text { examined by dermoscopy? }\end{array}$} & $\begin{array}{l}\text { Q11 If you use a sunscreen cream, indicate for how many } \\
\text { years }\end{array}$ & 1.01 & $1.001-1.02$ & 0.002 \\
\hline & $\begin{array}{l}\text { Q14 If you repeat sunscreen application, after how many } \\
\text { hours do you reapply? (If you do not reapply, type 0) }\end{array}$ & 1.06 & $1.02-1.1$ & 0.004 \\
\hline & Q17 What SPF value do you use? & 1.0054 & $1.0015-1.0093$ & 0.007 \\
\hline & $\begin{array}{l}\text { Q28 Do you usually wear protective eyeglasses when using } \\
\text { a tanning bed? }\end{array}$ & 1.27 & $1.11-1.45$ & $<0.001$ \\
\hline & $\begin{array}{l}\text { Q30 Do you know that a history of sunburn increases the } \\
\text { risk of melanoma up to five fold? }\end{array}$ & 1.37 & $1.16-1.63$ & $<0.001$ \\
\hline
\end{tabular}




\section{Characteristics of dermoscopic examinations conducted (Table 3)}

Individuals who had undergone dermoscopic assessment were examined by doctors using several approaches, including the evaluation of only one melanocytic lesion, the examination of multiple melanocytic lesions, the examination of only those lesions that concerned the patient and that the patient had requested to be evaluated, and the examination of only those lesions chosen by the physician (presented in Table 3 ).

Survey respondents who had only one melanocytic lesion examined by dermoscopy during a single visit were mostly men, worked outdoors proportionally more hours (during the day), more frequently chose a sunscreen cream depending on the UVA-protection factor or anti-UVA-PPD value, and were aware of a higher risk of melanoma due to sunburn.

This group was also characterized by the more frequent use of tanning beds without clothing and the use of protective eyeglasses. In addition, these respondents infrequently understood that regular exposure to the sun increases the risk of melanoma (Q47a).

Persons who underwent examination of multiple melanocytic lesions by dermoscopy during a single visit were more frequently inhabitants of larger locales and highly educated, performed more frequent applications of sunscreen cream after each emergence from the water, used sunscreens with higher SPF values, and were aware that melanoma is one of the most malignant types of cancer (Q47c). Individuals who requested dermoscopic examination during a single visit for melanocytic lesions that concerned them were more frequently better educated (had completed high school). They also used sunscreens with higher SPF values and were aware that melanoma was one of the most malignant types of cancer (Q47d).

Respondents who underwent dermoscopic examination for only those lesions selected by a physician (during a single visit) were more likely to be inhabitants of larger cities, were aware of the malignant nature of melanoma, and were able to divide their skin into prototypes depending on responsiveness to sunlight and the appearance of sunburn or a tan. Moreover, these individuals had relatively low skin phototypes according to the Fitzpatrick skin types (Q47e). Individuals who had never been examined by dermoscopy were much younger, spent significantly more time (minutes) in a tanning bed during one session, less frequently wore protective eyeglasses in a tanning bed, less frequently used tanning beds clothed and were less likely to know that melanoma is one of the most malignant types of cancer. These respondents also repeated the application of sunscreen cream less frequently during one sunbathing session and used sunscreens with lower SPF values (Q47f).

\section{Influence of sources of knowledge regarding the necessity of dermoscopic examination (Table 4)}

\section{Information obtained from the media and press: television and magazines}

The respondents who became aware of the need for dermoscopic examination from television sources were more likely to spend much more time (during the day) working outdoors and more frequently tanned in a tanning bed during the year (Q49a). The respondents who became aware of the crucial role of dermoscopic examination from magazines were more often female and resided in smaller locales (Q49d).

\section{Information obtained from shared information, prevention campaigns, schools, and physicians}

The respondents who became aware of the need for dermoscopic examination through shared information/ prevention efforts more often used sunscreens with lower SPF values despite more frequently having knowledge of the malignancy of melanoma (Q49e). The respondents whose awareness of the significance of dermoscopic examination was traced to a doctor more often knew that regular exposure to sunlight could increase the risk of melanoma, and these individuals also worked outdoors for shorter time periods. Although those surveyed had been sunburned less often before the age of 18 years, they did not repeat sunscreen application every hour (Q49f). Individuals who were informed about dermoscopic examination at school were more likely to wear protective eyeglasses in a tanning bed. These respondents also tanned less frequently in tanning beds but were less likely to select a sunscreen cream based on the UVA-protection factor or anti-UVA-PPD value (Q49g). Unfortunately, we also observed respondents in the study group who were unaware of dermoscopic examination (10.7\%, approximately one-tenth of the individuals surveyed). These individuals more regularly enjoyed sunbathing outdoors and used sunscreen creams during sunbathing (Q49h2).

\section{Discussion}

Factors that have been associated with the diagnosis of thinner melanomas include the recognition of lesions by a physician, the presence of clinically atypical nevi, and a higher educational level and detection-promoting awareness and attitude of the patient [12]. The results of our survey revealed generally good knowledge about and awareness of the melanoma risk among the examined population. Despite that, a subset of individuals was identified who engaged in risky sun exposure behaviors and who had never been examined by dermoscopy. Reported behaviors regarding tanning bed use and sunburn pose risks of a further increase in the incidence of skin 
Table 3. Characteristics of the dermoscopic examinations conducted in the examined subgroup

\begin{tabular}{|c|c|c|c|c|}
\hline Response & Predictor & Odds ratio & $95 \% \mathrm{Cl}$ & $P$-value \\
\hline \multirow{7}{*}{$\begin{array}{l}\text { Q47a How many nevi } \\
\text { during one visit were } \\
\text { examined by dermoscopy? } \\
\text { a) } 1\end{array}$} & Q2 Your gender & 0.76 & $0.65-0.89$ & $<0.001$ \\
\hline & $\begin{array}{l}\text { Q6 For how long (during the day) do you usually work } \\
\text { outdoors? }\end{array}$ & 1.04 & $1.003-1.07$ & 0.027 \\
\hline & $\begin{array}{l}\text { Q18 Do you choose a sunscreen cream based on a UVA- } \\
\text { protection factor value or anti-UVA-PPD? }\end{array}$ & 1.26 & $1.11-1.44$ & $<0.001$ \\
\hline & $\begin{array}{l}\text { Q21 Did you know that regular exposure to sunlight increases } \\
\text { the risk of melanoma? }\end{array}$ & 0.65 & $0.5-0.86$ & 0.003 \\
\hline & Q27 Do you use tanning beds unclothed? & 1.19 & $1.03-1.36$ & 0.017 \\
\hline & $\begin{array}{l}\text { Q28 Do you usually wear protective eyeglasses in tanning } \\
\text { beds? }\end{array}$ & 1.2 & $1.05-1.37$ & 0.008 \\
\hline & $\begin{array}{l}\text { Q30 Do you know that a history of sunburn increases the risk } \\
\text { of melanoma up to five fold? }\end{array}$ & 1.2 & $1.02-1.42$ & 0.031 \\
\hline \multirow{5}{*}{$\begin{array}{l}\text { Q47c How many nevi were } \\
\text { examined by dermoscopy } \\
\text { during one visit? } \\
\text { c) All }\end{array}$} & Q3 Place of residence & 1.4 & $1.2-1.63$ & $<0.001$ \\
\hline & Q4 Education - level of schooling completed & 2.01 & $1.4-2.87$ & $<0.001$ \\
\hline & $\begin{array}{l}\text { Q15 Do you apply sunscreen cream each time you come out of } \\
\text { the water? }\end{array}$ & 1.82 & $1.18-2.82$ & 0.007 \\
\hline & Q17 What SPF value do you use? & 1.02 & $1.01-1.03$ & $<0.001$ \\
\hline & $\begin{array}{l}\text { Q37 Did you know that melanoma is one of the most } \\
\text { malignant types of cancer? }\end{array}$ & 13.95 & $1.9-102.35$ & 0.01 \\
\hline \multirow{3}{*}{$\begin{array}{l}\text { Q47d How many nevi were } \\
\text { examined by dermoscopy } \\
\text { during one visit? } \\
\text { d) Only those I was } \\
\text { concerned and for which } \\
\text { I requested an examination }\end{array}$} & Q4 Education - level of schooling completed & 1.35 & $1.04-1.75$ & 0.026 \\
\hline & Q17 What SPF value do you use? & 1.01 & $1.001-1.02$ & 0.004 \\
\hline & $\begin{array}{l}\text { Q37 Did you know that melanoma is one of the most } \\
\text { malignant types of cancer? }\end{array}$ & 2.19 & $1.01-4.74$ & 0.048 \\
\hline \multirow{4}{*}{$\begin{array}{l}\text { Q47e How many nevi were } \\
\text { examined by dermoscopy } \\
\text { during one visit? } \\
\text { e) Only those chosen by } \\
\text { the physician }\end{array}$} & Q3 Place of residence & 1.29 & $1.1-1.5$ & 0.001 \\
\hline & $\begin{array}{l}\text { Q33 Can you classify your skin according to phototype } \\
\text { depending on its responsiveness to sunlight and the } \\
\text { appearance of sunburn or a tan? }\end{array}$ & 2.51 & $1.43-4.41$ & 0.001 \\
\hline & Q34 How would you describe your skin phototype? & 0.63 & $0.46-0.86$ & 0.003 \\
\hline & $\begin{array}{l}\text { Q37 Did you know that melanoma is one of the most } \\
\text { malignant types of cancer? }\end{array}$ & 5.42 & $1.32-22.21$ & 0.019 \\
\hline \multirow{7}{*}{$\begin{array}{l}\text { Q47f How many nevi were } \\
\text { examined by dermoscopy } \\
\text { during one visit? } \\
\text { f) This type of examination } \\
\text { was not performed }\end{array}$} & Q1 Your age [years] & 0.9918 & $\begin{array}{l}0.9871- \\
0.9965\end{array}$ & $<0.001$ \\
\hline & $\begin{array}{l}\text { Q13 Do you repeat the application of sunscreen cream during } \\
\text { sunbathing sessions? }\end{array}$ & 0.82 & $0.72-0.93$ & 0.002 \\
\hline & Q17 What SPF value do you use? & 0.9951 & $\begin{array}{l}0.9915- \\
0.9988\end{array}$ & 0.009 \\
\hline & $\begin{array}{l}\text { Q25 How many minutes is your average single tanning bed } \\
\text { session? }\end{array}$ & 1.03 & $1.01-1.05$ & 0.01 \\
\hline & Q27 Do you use tanning beds unclothed? & 0.82 & $0.7-0.96$ & 0.012 \\
\hline & $\begin{array}{l}\text { Q28 Do you usually wear protective eyeglasses in tanning } \\
\text { beds? }\end{array}$ & 0.84 & $0.74-0.96$ & 0.008 \\
\hline & $\begin{array}{l}\text { Q37 Did you know that melanoma is one of the most } \\
\text { malignant types of cancer? }\end{array}$ & 0.78 & $0.64-0.93$ & 0.007 \\
\hline
\end{tabular}


Table 4. Influence of sources of knowledge regarding the need for dermoscopic examination

\begin{tabular}{|c|c|c|c|c|}
\hline Response & Predictor & Odds ratio & $95 \% \mathrm{Cl}$ & $P$-value \\
\hline \multirow{2}{*}{$\begin{array}{l}\text { Q49a How did you } \\
\text { become aware of the } \\
\text { need for a dermoscopic } \\
\text { examination? } \\
\text { a) TV }\end{array}$} & $\begin{array}{l}\text { Q6 For how long (during the day) do you usually work } \\
\text { outdoors? }\end{array}$ & 1.08 & $1.02-1.14$ & 0.004 \\
\hline & $\begin{array}{l}\text { Q24 How many times a year on average do you tan in } \\
\text { tanning beds? }\end{array}$ & 1.01 & $1.002-1.03$ & 0.025 \\
\hline \multirow{2}{*}{$\begin{array}{l}\text { Q49d How did you } \\
\text { become aware of the } \\
\text { need for a dermoscopic } \\
\text { examination? } \\
\text { d) Magazines }\end{array}$} & Q2 Your gender & 0.74 & $0.58-0.96$ & 0.022 \\
\hline & Q3 Place of residence & 0.92 & $0.86-0.99$ & 0.018 \\
\hline \multirow{2}{*}{$\begin{array}{l}\text { Q49e How did you } \\
\text { become aware of the } \\
\text { need for a dermoscopic } \\
\text { examination? } \\
\text { e) Shared information/ } \\
\text { prevention efforts }\end{array}$} & Q17 What SPF value do you use? & 0.9922 & $0.986-0.9984$ & 0.014 \\
\hline & $\begin{array}{l}\text { Q33 Can you classify your skin according to phototype } \\
\text { depending on its responsiveness to sunlight and } \\
\text { the appearance of sunburn or a tan? }\end{array}$ & 1.31 & $1.06-1.63$ & 0.014 \\
\hline \multirow{4}{*}{$\begin{array}{l}\text { Q49f How did you } \\
\text { become aware of the } \\
\text { need for a dermoscopic } \\
\text { examination? } \\
\text { f) From the doctor }\end{array}$} & Q7 For how long do you usually work outdoors? & 0.9 & $0.82-0.99$ & 0.032 \\
\hline & $\begin{array}{l}\text { Q14 If you repeat sunscreen applications, after how many } \\
\text { hours do you reapply? (If you do not reapply, type 0) }\end{array}$ & 0.89 & $0.82-0.96$ & 0.003 \\
\hline & $\begin{array}{l}\text { Q21 Did you know that regular exposure to sunlight } \\
\text { increases the risk of melanoma? }\end{array}$ & 2.71 & $1.3-5.65$ & 0.008 \\
\hline & $\begin{array}{l}\text { Q32 How many times did you have sunburn before the age } \\
\text { of } 18 \text { years? }\end{array}$ & 0.97 & $0.94-0.99$ & 0.03 \\
\hline \multirow{3}{*}{$\begin{array}{l}\text { Q49g How did you } \\
\text { become aware of the } \\
\text { need for a dermoscopic } \\
\text { examination? } \\
\text { g) In school }\end{array}$} & $\begin{array}{l}\text { Q18 Do you choose a sunscreen cream based on a UVA- } \\
\text { protection factor value or anti-UVA-PPD? }\end{array}$ & 0.65 & $0.48-0.88$ & 0.005 \\
\hline & Q22 Do you tan in tanning beds? & 0.63 & $0.41-0.96$ & 0.033 \\
\hline & $\begin{array}{l}\text { Q28 Do you usually wear special eyeglasses in a tanning } \\
\text { bed? }\end{array}$ & 1.47 & $1.09-1.98$ & 0.011 \\
\hline \multirow{2}{*}{$\begin{array}{l}\text { Q49h2 How did you } \\
\text { become aware of the } \\
\text { need for a dermoscopic } \\
\text { examination? } \\
\text { h) Other; I've never known } \\
\text { about such an examination }\end{array}$} & Q8 Do you like sunbathing outdoors? & 1.38 & $1.003-1.89$ & 0.047 \\
\hline & $\begin{array}{l}\text { Q10 Do you regularly use sunscreen creams while } \\
\text { sunbathing? }\end{array}$ & 1.52 & $1.14-2.03$ & 0.004 \\
\hline
\end{tabular}

cancer. Study participants who were unfamiliar with dermoscopy were more likely to enjoy outdoor sunbathing and to use sunscreen creams more regularly during sunbathing. It is also alarming that risky behaviors including not complying with the safe tanning guidelines were observed among young people and may therefore have an impact on the future incidence of melanoma. $A$ recent study by Boyle et al. indicated that skin cancer knowledge in 2008 was high in a study group of 3,623 respondents [13]. Notwithstanding, the role of doctors in melanoma diagnosis is important. In a study by Klein et al. among 50 patients with histopathologically proven melanoma, 74\% were referred by dermatologists, 16\% were referred by primary caregivers, and $10 \%$ presented independently or were under the supervision of an operating plastic surgeon [14]. Dermoscopy is a gold-standard method for the evaluation of melanocytic lesions [3], and the use of dermoscopy during dermatologic evaluation prolongs the total examination time by only $72 \mathrm{~s}$ [15]. For this reason, the regular use of dermoscopy is worthwhile, and this tool should always be used to assess skin lesions [15]. In the differential diagnosis of melanocytic lesions, a description of changes in the melanocytic skin profile may be more useful when examined in the context of a comprehensive assessment of all skin lesions [16]. Moreover, physicians should be aware of the importance of examining all lesions, as total dermoscopy is not performed in all cases. Current melanoma screening guidelines in the United States are inconsistent among various organizations, and therefore rates of both physician and patient skin examinations are low. Therefore, patient and provider education is necessary to ensure that appropriate patients receive recommended screening in the United States [17]. Although the use of der- 
moscopy is increasing in popularity among dermatologists, there is still a need for improvement. For example, $42.7 \%$ of US dermatologists reported no prior experience with dermoscopy. Thus, the accessibility of dermoscopy training should be improved, and the learning methods should be more approachable and unified [18]. Our data present that a significant number of people who are at risk of melanoma have also never been examined by dermoscopy and are unaware of this type of the diagnostic method. Moreover these individuals are more likely to engage in risky sun exposure behaviors that favor the development of melanoma. In addition, inappropriate methods of dermoscopic examination among doctors have been noted (the examination of only one lesion, either chosen by the patient or selected by a doctor). A recently published nationwide survey concerning dermoscopy practice in Europe revealed that dermoscopy helps to detect melanoma earlier and to perform fewer biopsies according to $86.6 \%$ and $74.6 \%$, respectively [19]. Laypersons may be able to use dermoscopy to identify more melanomas than naked eye examination alone as well [20]. The mass media, especially television and magazines, can significantly affect the frequency of dermoscopic examination and encourage desired, healthpromoting behaviors in the key target-group audience [21]. However, an analysis of the top ten most-read newspapers in the United Kingdom revealed that in relation to the incidence of melanoma, there was an over-representation of articles dedicated to melanoma in the tabloids, while the number of publications in the so-called opinion-forming press was relatively low [22]. Among the 2,659 participants of Sweden's 2008 "Euromelanoma Day", the majority $(1,623)$ gained knowledge about this campaign from the press (61\%), by word of mouth (326 or $12 \%$ ), or from the Internet (187 or $7 \%$ ), radio (133 or $5 \%$ ) and television (110 or 4\%) [23]. Our data also showed that respondents gained knowledge about dermoscopic examination from television and magazines. Therefore, in the future, greater mass media attention should be focused on self-skin examination as well as dermoscopic examination during dermatologist consultations. The positive influence of television and radio sources has also been noted in New Zealand, where, after information about weekend sun exposure was delivered, awareness of the burn time for the corresponding ultraviolet index increased from 43\% to 89\% [24]. During the skin cancer prevention campaign among beachgoers of the western Costa del Sol, most of them reported high-risk sun exposure and significant numbers of clinically suspicious lesions. This campaign was followed not only by local but also regional and national media [25].

Our web-based study could have been prone to some types of bias. First of all, the volunteer-bias should be taken into consideration as our sample members were self-selected, voluntarily participating in this cross-sectional study. The risk of non-response bias could not be excluded as well, but the possible differences between responders and non-responders could not be demonstrated because we do not have any information regarding those who did not participate. Another limitation of this study could be the selection bias associated with the level of Internet access (66\% of Polish citizens over the age of 15) [26] as well as with the need for sufficient Internet skills among respondents in order to participate. Selection of respondents whose characteristics differ from the target population poses a threat to qualitative, and not quantitative studies [27]. In general, people who participate are more sociable, educated as well as often come from a higher socio-economic class [28].

Volunteer participants seem to be more interested in the subject. Assuming this phenomenon occurs in case of our research, the real situation might be even worse than it was reported. Approximately four-fifths of our study participants were women, which may indicate that this group has a higher interest in the subject of skin diseases, especially melanoma. Other studies regarding survey methodology have revealed that women are more likely to participate voluntarily, which is consistent with the gender proportion that we have noted. Moreover, the literature provides examples of the positive role played by women regarding their assistance in the examination of their partner's skin [29]. Given the above, generalizability of presented results might be limited. However it is necessary to conduct this type of research in other countries.

\section{Conclusions}

The management of melanoma and melanocytic lesions as well as the knowledge of effective sun care are good among the Polish population. However, certain improvement is needed, particularly in the high-risk group of individuals who have never been examined by dermoscopy and were unaware of this diagnostic method. Therefore, the main outcome of this study is a significant need for educational campaigns, particularly mass media campaigns targeting individuals at the highest risk of melanoma. Moreover, there is a need for improvement in dermoscopy training among physicians, including dermatologists. Physicians who perform dermoscopy should be aware of possible errors arising from the failure to follow proper test procedures (procedural or technical errors) and knowledge-based mistakes related to the lack of sufficient familiarity and experience in dermoscopy [30].

\section{Acknowledgments}

We would like to thank all the study's participants for their involvement.

The name of the department in which the study was conducted, and the name of the department to which the work should be attributed: The Center for Cancer Pre- 
vention and Treatment, Fliegera 16, Katowice, Poland and Department of Conventional and Intraoperative Radiotherapy, Maria Skłodowska-Curie Memorial Cancer Centre and Institute of Oncology Gliwice Branch, Wybrzeże Armii Krajowej 15, Gliwice, Poland.

\section{Conflict of interest}

The authors declare no conflict of interest.

\section{References}

1. Jerant AF, Johnson JT, Sheridan CD, Caffrey TJ. Early detection and treatment of skin cancer. Am Fam Physician 2000; 62: 357-68, 375-6, 381-2.

2. Ferlay J, Soerjomataram I, Ervik M, et al. GLOBOCAN 2012 v1.0, Cancer Incidence and Mortality Worldwide: IARC CancerBase No. 11 [Internet]. Lyon, France: International Agency for Research on Cancer; 2013. http://globocan.iarc.fr. Accessed 20 June 2016.

3. Stratigos AJ, Katsambas AD. The value of screening in melanoma. Clin Dermatol 2009; 27: 10-25.

4. European Health for All Database (HFA-DB). World Health Organization, European Office, Copenhagen, Denmark. http://data.euro.who.int/hfadb/. Accessed 21 February 2016.

5. Blum A, Hofmann-Wellenhof R, Luedtke $H$, et al. Value of the clinical history for different users of dermoscopy compared with results of digital image analysis. J Eur Acad Dermatol Venereol 2004; 18: 665-9.

6. Kittler H, Pehamberger H, Wolff K, Binder M. Diagnostic accuracy of dermoscopy. Lancet Oncol 2002; 3: 159-65.

7. Argenziano G, Cerroni L, Zalaudek I, et al. Accuracy in melanoma detection: a 10-year multicenter survey. J Am Acad Dermatol 2012; 67: 54-9.

8. Kamińska-Winciorek G, Gajda M, Wydmański J, Tukiendorf A. What do Web users know about skin self-examination and melanoma symptoms? Asian Pac J Cancer Prev 2015; 16: 3051-6.

9. Gajda M. Polski Serwis Naukowy. [http://www.naukowy.pl].

10. Google Docs. [http://docs.google.com].

11. R Core Team R. A language and environment for statistical computing. R Version 3.0.2. Vienna: R Foundation for Statistical Computing [http://cran.R-project.org].

12. Swetter SM, Layton CJ, Johnson TM, et al. Gender differences in melanoma awareness and detection practices between middle-aged and older men with melanoma and their female spouses. Arch Dermatol 2009; 145: 488-90.

13. Boyle R, O'Hagan AH, Donnelly D, et al. Trends in reported sun bed use, sunburn, and sun care knowledge and attitudes in a U.K. region: results of a survey of the Northern Ireland population. Br J Dermatol 2010; 163: 1269-75.

14. Klein D, Westreich M, Shalom A. Accuracy of malignant melanoma detection in the community. Acta Dermatovenerol Croat 2012; 20: 165-9.

15. Zalaudek I, Kittler H, Marghoob AA, et al. Time required for a complete skin examination with and without dermoscopy: a prospective, randomized multicenter study. Arch Dermatol 2008; 144: 509-13.

16. Argenziano G, Cacitrala C, Argido M. Dermoscopy of patients with multiple nevi: improvemend management recommendations using a comparative diagnostic approach. Arch Dermatol 2011; 147: 46-9.
17. Mayer JE, Swetter SM, Fu T, Geller AC. Screening, early detection, education, and trends for melanoma: current status (2007-2013) and future directions: Part II. Screening, education, and future directions. J Am Acad Dermatol 2014; 71: 611.e1-10.

18. Noor O 2nd, Nanda A, Rao BK. A dermoscopy survey to assess who is using it and why it is or is not being used. Int J Dermatol 2009; 48: 951-2.

19. Moulin C, Poulalhon N, Duru G, et al. Dermoscopy use by French private practice dermatologists: a Nationale survey. Br J Dermatol 2013; 168: 74-9.

20. Luttrell MJ, McClenahan P, Hofmann-Wellenhof R, et al. Laypersons' sensitivity for melanoma identification is higher with dermoscopy images than clinical photographs. $\mathrm{Br}$ J Dermatol 2012; 167: 1037-41.

21. Kemp GA, Eagle L, Verne J. Mass media barriers to social marketing interventions: the example of sun protection in the UK. Health Promot Int 2011; 26: 37-45.

22. Williamson JML, Jones IH, Hocken DB. How does the media profile of cancer compare with prevalence? Ann R Coll Surg Engl 2011; 93: 9-12.

23. Paoli J, Danielsson M, Wennberg AM. Results of the 'Euromelanoma Day' screening campaign in Sweden 2008. J Eur Acad Dermatol Venereol 2009; 23: 1304-10.

24. Bulliard JL, Reeder A. Getting the message across: sun protection information in media weather reports in New Zealand. N Z Med J 2001; 114: 67-70.

25. de Troya-Martín M, Delgado-Sánchez N, Blázquez-Sánchez $\mathrm{N}$, et al. Skin cancer prevention campaign aimed at beachgoers on the Costa del Sol (southern Spain). Int I Dermatol 2014; 53: e526-30.

26. World Internet Users Statistics and 2015 World Population Stats [http://www.internetworldstats.com/stats.htm]. Accessed 21 January 2016.

27. Van Gelder MMHJ, Bretveld RW, Roeleveld N. Web-based questionnaires: the future in epidemiology? Am J Epidemiol 2010; 172: 1292-8.

28. Sedgwick P. Questionnaire surveys: sources of bias. BMJ 2013; 347: f5265.

29. Weinstock MA, Martin RA, Risica PM, et al. Thorough skin examination for the early detection of melanoma. Am J Prev Med 1999; 17: 169-75.

30. Kaminska-Winciorek G, Placek W. The most common mistakes on dermatoscopy of melanocytic lesions. Postep Dermatol Alergol 2015; 32: 33-9. 